\title{
The Emperor's new clothes: living skins and the reconsideration of the post-war office tower
}

\author{
S. Holmes ${ }^{1}$, J. Maze ${ }^{2}$ \& M. McGlothlin ${ }^{2}$ \\ ${ }^{1}$ Holmes Hepner and Associates Architects, Tampa, Florida, USA \\ ${ }^{2}$ School of Architecture, University of Florida, Gainesville, Florida, USA
}

\begin{abstract}
Whether in response to the growing concerns of climate change or born instead of a fascination in the material advancements of the last decade, the architectural opportunities in sustainability are substantial and plentiful. Arguments run the gamut of professional domains, stretching across the numerous aspects of industry, manufacturing and power generation, which in turn carry the parallel disciplinary interests of architecture, engineering, the social sciences, economics and public policy. Much of the attention garnered by the sustainability movement has highlighted new buildings proper as they provide the greatest visibility. There is however an immense and relatively untapped reservoir of opportunities with the office towers of the post-war era. The earlier considerations to the benefits of natural ventilation were dismissed in favour of the idiomatic environmental control systems, vis-à-vis reliance upon mechanical systems to compensate for the discarded natural techniques, resulting in sealed work environments mapped by the rampant growth of "sick building syndrome" nomenclature. This paper will offer a reconsideration of the otherwise overlooked building type - the post-war high-rise in a zeitgeist of passive and active environmental provisions. By exploring this typology, crafted within the greatest aspirations of its own era, the ideas of re-use and adaptation can be expanded beyond the limits of historic structures to include buildings that were once considered to be icons of technological advancement. Instead of demolishing, the notion of re-articulating the very essence of qualitative lifesupport is of an immediate and ever-present importance.
\end{abstract}

Keywords: biomimicry, Florida, office tower, adaptive re-use. 


\section{Biomimicry and its application}

Architecture could be stated as being in a constant state of flux, drifting between its inorganic material presence and the organic origins to which its development is bound. Examples of these organic origins are plentiful and immediate and can quickly be extended beyond biological iconography, to include the most fundamental manners of architectural making and thinking. The simplest considerations of the human body in the scaling of space sheds light on this idea, as do the extensions of the Fibonacci series and its proportional counterpart, the golden section, yet in each case, the specific relationships to the organic realm tend to inform only the building's appearance, which raises the question of other potentials that remain untapped. It is not natural symbolism, as in the horizoninspired horizontality of the prairie houses, or the acanthus interpretation on Corinthian capitals from the monument to Lisicrate in Athens, but instead the study and emulation of how a natural organism functions and the resultant formal vocabulary that drives this research.

American environmental activist and author Janine M. Benyus presents the following criteria for biomimicry: "Does it run on sunlight? Does it use only the energy it needs? Does it fit form to function? Does it recycle everything? Does it reward cooperation? Does it bank on diversity? Does it utilize local expertise? Does it curb excess from within? Does it tap the power of limits? Is it Beautiful?" [1]. Following these tenets, application of basic principles discovered through biomimicry can yield a building that responds to its user while mediating the environment outside. The building should breathe, grow, open up to catch the sun's rays, shield its interior from the solar thermal gain, and extract energy, water and light from the environment in order to provide all the resources from the immediate environment rather consuming and shipping them from afar. In nature, this is how an organism works. It consumes local resources and then gives off waste that in turn is used for food in another organic system. Each organism is a link in a greater system: a part of a whole. It consumes and provides at the same time.

This organic inspiration begs the question of a biomorphic building skin that takes its genesis in the deep conceptual basis of biomimicry in lieu of a more typical superficial appliqué. Italian architect and theorist Paolo Portoghesi argues that even though early twentieth-century proponents of "organic architecture" espoused the aesthetic qualities of nature, more recent architects aided by the biological sciences consider the functionality of natural systems rather than their appearances alone. These earlier theorists "did not realize that for nature, appearances are no less important than their corresponding functions and that, for all their splendid independence, living organisms are made to interact with both organic and inorganic environmental reality and that this interaction is one of the reasons that determines their forms" [2]. It is this organic functionalism that possesses the potential for creating a healthier, less destructive architecture appropriate for a fragile global environment in crisis.

So in this vein, in the consideration of a new skin for an existing office tower, one looks to nature for ways in which by virtue of biomimetics the building can 
be made to operate in a more sustainable manner. Such possible sources of study include how does a leaf function to absorb light, circulate water, resist tearing in the wind, and expend oxygen?

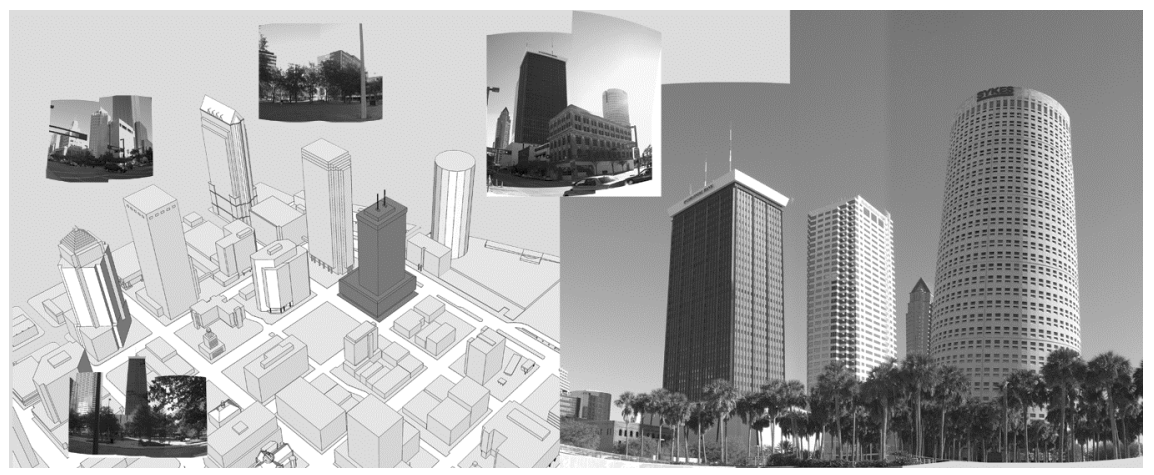

Figure 1: $\quad$ Site model and existing office tower.

\section{Typology and context}

While the most seductive aspects of a biomimetic design process may best be advanced through a clean slate, this exploration opted for a more challenging approach by taking the pre-existing office block as the operative constraint. Much of the post-war American urban fabric is defined by the loose collection of expansive single-family housing developments clustered around a mid-density urban core. Older, more established cities such as Boston or Chicago had an architectural heritage into which more contemporary projects could be carefully inserted, while the younger cities such as Atlanta, Dallas and Tampa offered a less constrained terrain in which to build. The larger office buildings that emerged in these contexts were icons of their time, bold in form and unashamedly modern - a collective architectural language that spoke directly of technology's prowess via undifferentiated reflective hermetic skins. Though advanced for their time, in retrospect these towers have proven increasingly problematic, born of an ideological stance unconcerned with the climatic and contextual issues that frame so much of the contemporary architectural discourse. This dysfunctional shell beckons for a reconsideration that can better demonstrate a principled approach toward the skin as an adaptable, responsive and contextually complementary system - or in a word, living.

The Park Tower, completed in 1972 was the tallest building in Tampa and third largest in Florida, rising 460 feet over the course of its 36 stories [3]. In the three decades since its completion, the Park has undergone an evolution typical to buildings of size and era, transforming from a once heralded status at the edges of technological advancement to becoming effectively trapped by the forces of its own making. Its former command of the city has drifted away, leaving it a hulking mass within the evolving context, unresponsive to increasing energy costs. In 2006, the Sterling American Property inc. of New York 
purchased the Park at a selling price of roughly $\$ 50$ million. Following the purchase, Sterling announced its plans for a modest remodeling, the first in the three decades since its construction [4].

The city of Tampa rests on the Western edge of the Florida Peninsula at latitude 27 degrees, roughly the midpoint of the western coastline with the Gulf of Mexico. Falling into a subtropical climatic zone, the greater Tampa region is characterized by long, warm and humid summers with temperatures ranging from 70-90 Fahrenheit. The winter months are mild, with the temperature ranging from 50-70 degrees. The relative humidity is high, though fairly consistent at $70 \%$ throughout the year. Humidity levels can be extreme in the summer, more so during morning hours as the afternoon breezes held to decrease humidity levels. The entire peninsula is prone to hurricane events, which occur with greater frequency between the months of June and October. Westerly winds off of the gulf are consistent throughout the year, with additional increased easterly winds during the late spring and summer, and northerly winds becoming more predominant during the winter months [5]. Average temperatures tend to fall within reasonable comfort zones (68-80 degrees Fahrenheit) for much of the year, with only afternoons of the hottest months exceeding this range. This characteristic alone would make natural ventilation techniques highly effective, though the humidity levels are such that mechanical dehumidification is required in order to achieve acceptable latent heat.

\section{Redressing - elements and systems}

Given these characteristics, the Park is ideal to fuel this hypothetical study which took as its goal the analysis, assessment and redevelopment of Park Tower though the principles of biomimetics. The contextual and climatic challenges framed much of the study, though these constraints did little to diminish the enthusiasm for the project. Though still utopian in its aspiration, the proposal has followed a systemic process of inception and development, attempting to successfully incorporate both the radical and reasonable. The building skin received the initial focus, but it quickly lead to a more assertive questioning of the building volume, program and infrastructure. A number of the final decisions within the proposal, such as relocating the elevators to the building edge, may expose an overly idealized manner of thinking, though the intent of the work was never to be fully obedient to the mindset of the developer. Design parameters were instead allowed some latitude within the process of discovery with the hopes of depositing more questions of future possibilities than in providing conclusions that are have already taken for granted.

\subsection{Solar concerns}

When originally built, the Park was a singular tower with unblocked views in all directions. This made for extreme solar exposure on the east, south and west facades. This degree of solar exposure allowed for some sunlight penetration into the floor plate while also introducing a significant degree of solar heat gain. 
In the decades since the Park's construction, other towers have been developed in downtown Tampa, impacting the degree of solar exposure the Park receives. Though some degree of blockage occurs on the southern and western facades due to the proximity of other buildings, significant solar exposure still remains on the western face of the building volume. This is most prominent at the upper floors, with only marginal solar exposure occurring in the bottom five stories.

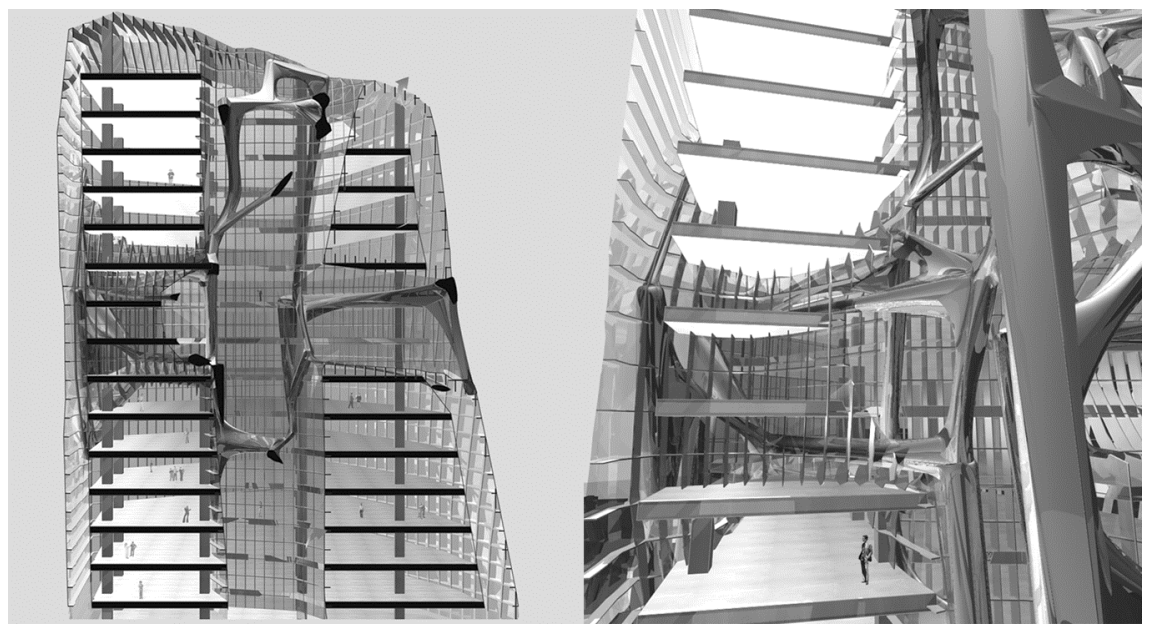

Figure 2: $\quad$ Renderings of sectional model and interior atrium.

\subsubsection{Skin and orientation}

Redevelopment of the building skin includes consideration for the specific orientation of each face of the larger building volume. The northern face of the building can remain open to glazing with shading methods oriented vertically to buffer the more horizontal sun angles that occur in the early and late hours of the winter. The south, east and west facades require direct control of sun penetration, which is handled through two strategies, the first involving the thickening of the depth of the skin. For the east and west faces of the building volume, more horizontal sun angles are of greater concern, requiring solar screening, while the southern exposure can be more quickly mitigated through operable light baffles. Given the desire for adaptability, the overall solar screening system can be considered as the exterior-most layer of a double skinned enclosure system, with the primary role of mitigating sunlight penetration through dynamic control of each screening device akin to the sweeping canopies of the native live oak.

\subsubsection{Vegetated thickening}

The thickening of the skin provided valuable floor space for consideration as a vegetated surface. This approach allows for ambient cooling of the airspace between the building volume edge and the conditioned space, reducing overall heat transference through the skin, resulting in a respective reduction in the 
overall cooling load. Additionally, the vegetation provides additional shading for the east and west facades, as well as allowing for additional cooling of air pulled through the hollowed concreted slab structure below each planter.
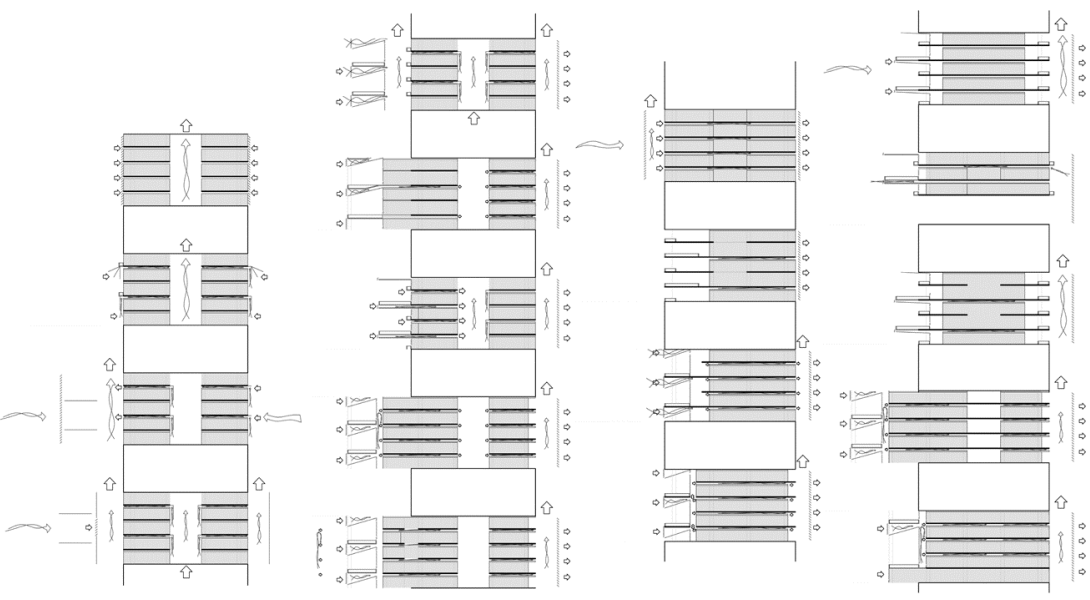

Figure 3: Sectional ventilation strategies with and without central core.

\subsection{Wind harvesting}

The systemic strategies for incorporating wind as a design element occur in two manners, first through internal openings and reordering of program for greater porosity, and secondly as a large, sheath-like sail that wraps much of the existing building. The lightweight, adjustable sail structure, which also serves as the primary shading system, opens and closes to better capture and direct prevalent winds while also offering protection from the common but infrequent tropical storms and hurricanes. Capturing cool morning breezes during the summer and funneling them along the concrete structure expands the thermal absorptive capacity of the structure, while also transferring and removing residual heat. Further, a controlled wind flow through the unconditioned public atria dispersed through the building volume enhances the microclimate of each space, while also helping to reduce the effective cooling load of adjoining conditioned program pieces.

\subsubsection{Ventilated skins}

The expansion of the building skin into multiple layers offers the opportunity for increased shading and vegetation, as well as avenues for contained ventilated air spaces. These continuous vertical channels become flues for the warmed air to rise through to an exhaust vent at the top edge. The more continuous breezes at the top of the building will encourage this air movement, drawing cooler air from lower levels of the building into the flue, further cooling the cavity between the skins and reducing the overall cooling load for the conditioned programmed spaces. 


\subsubsection{Ventilated slabs}

Working in combination with the ventilated skin, the primary concrete floor slabs will be developed with a second ventilated cavity on the underside of the slab. This plenum area will operate in coordination with the flue wall and the larger atria and internal vertical shafts that formerly housed the elevators, providing a second pathway for airflow, beginning within the flue, passing along the bottom of the concrete structure, then returning to an upward flow within the continuous internal vertical shafts. Like the flue wall, exhaust vents are controlled at the tower's termination, borrowing from the continuous breezes to better draw air along these paths.

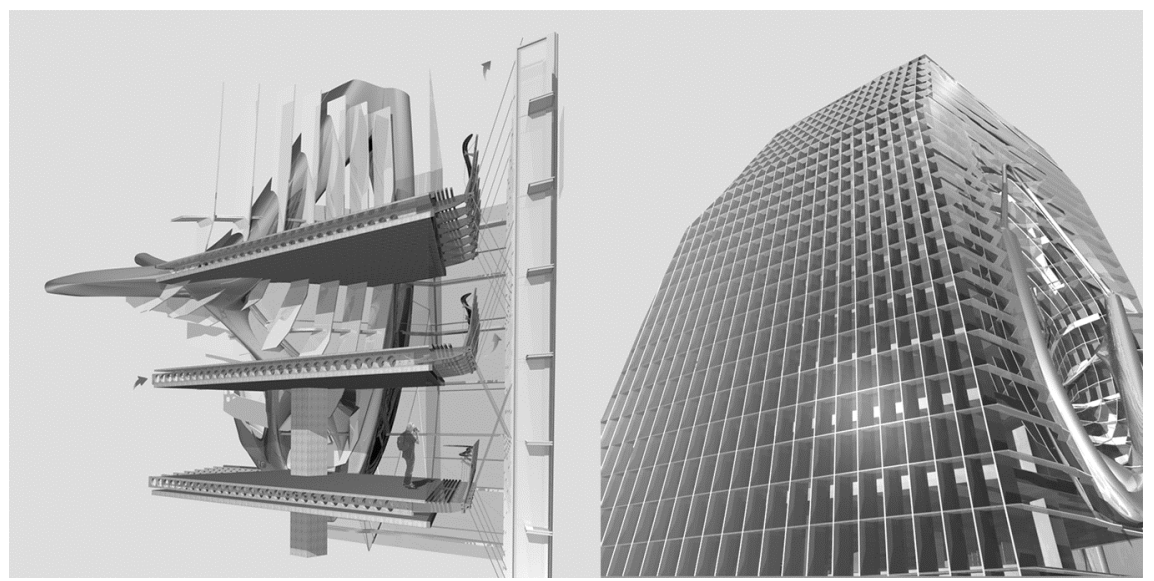

Figure 4: Renderings of cutaway section and exterior.

\subsection{Incessant moisture}

While this study has gone through great efforts to minimize the effects of solar gain through a systemic engagement of the building skin as an adaptable, living tectonic, the outcome of these techniques are fundamentally limited by the relative humidity levels that define so much of the Florida climate. As was noted earlier, the average temperatures for Tampa fall within inhabitable comfort zones for much of the year, suggesting that maximum passive cooling techniques could be universally employed. This immediate observation is however misleading since it does not fully account for the effects of latent heat. It is true that the sensible temperatures are largely manageable through passive techniques. Latent heat however proves a more demanding and unavoidable concern in overall cooling, demonstrating that the reduction of humidity is of greater importance than the actual cooling of the air.

The humidity levels are of such prominence in this context, the idea of flushing enclosed space with cool morning air tends only to introduce excessive moisture into the space, particularly when the highest relative humidity levels tend to occur in the morning hours. The strategies for moving air through the building skin and into areas internal to the building volume only occur within 
unconditional channels and plenums where humidity issues are of minimal concern. It is taken as a given that humidity reduction is required for conditioned program and that this dehumidification process will be needed for both fresh air introduction and for return air within the conventions of mechanical cooling. The larger parti of the scheme has attempted to break the program into somewhat smaller blocks of conditioned space, each incorporating a smaller dehumidification station. This allows for the condensate of each dehumidification station to be channeled back to the vegetated skins on the east, south and north facades for the purposes of irrigation.

\section{Outcomes and projections}

In many ways this project is a reflection of the ongoing growth of biomimetic strategies within the design fields, which is arguably still in a fledgling state of development. It is of particular importance as well that this collection of ideas and consecutive design proposals be judged in a context consistent with graduate study. This project was the Master Research Project for then graduate student Scott Holmes, with Professors Maze and McGlothlin serving as the graduate committee. While this pedagogical structure certainly benefits criticism more consistent to Architecture, the study quickly expanded beyond normal disciplinary boundaries, involving research topics, language and background skill sets to which the team was unfamiliar. This resulted in design proposals that are idealistic though inherently naïve as the project duration and tools at hand simply did not allow for a more nuanced and measured development. This caveat is not offered in defense of the project and is not intended to diminish its contributions. Rather it hopes to better explain this project as a preliminary foray into this growing field of research and inquiry. The coupling of biomimicry with the reconsideration of existing building skins will prove infinitely valuable, particularly in light of the recent volatility within the energy markets, as well as the increasingly problematic forecasts for hotter and wetter weather patterns in the coming decades.

In closing, the outcomes of this project are best considered as open-ended projections that will unfold over the coming years. Contemporary architectural practices in the United States are not well equipped to quickly integrate biomimetic design principles into practice, burdened by both a lack of expertise within the office and a marketplace that is slow to change course. These shifts and discussions are however on the horizon and will continue to grow, though only at a pace even with the patronage and encouragement of interested clients. Relative to biomimetics in design education, the current pedagogical methodologies are equally slow to change, bound by the common impediments of curricular restraints and bureaucratic procedures, as well as the ideological camps that are perhaps most pronounced within the academic realm. With that said, this project is indicative of the interests of students, who display a sincere interest in the broad aspects of sustainable design principles and corresponding debates over a new moral trajectory within the consideration of the built environment. It is on this line of thinking that biomimicry is best positioned - as 
a research topic with robust potentials for Architecture that have yet to be discovered.

\section{References}

[1] Benyus J.M., Biomimicry: Innovation Inspired by Nature, William Morrow and Co.: New York, p. 291,1997.

[2] Portoghesi, P., Nature and Architecture, Skira Editore: Milan, p. 39, 2000.

[3] Emporis, http://www.emporis.com/en/wm/bu/?id=parktower-tampa-fl-usa

[4] Cronan, C., Park Tower's new owners see potential in once-prominent building. Tampa Bay Business Journal, 17 February, 2006. Online. http://www.bizjournals.com/tampabay/stories/2006/02/20/focus2.html?jst=s cn hl

[5] Myers, R.L. \& Ewel, J.J., (eds). Ecosystems of Florida, University of Central Florida Press: Orlando, p. 11-35, 1990. 